\title{
Resolution of persistent corneal erosion after administration of topical rebamipide
}

This article was published in the following Dove Press journal:

Clinical Ophthalmology

28 August 2012

Number of times this article has been viewed

\author{
Tomoyuki Kashima ${ }^{1,2}$ \\ Hideo Akiyama' \\ Fumihide Miura ${ }^{2}$ \\ Shoji Kishi'
}

'Department of Ophthalmology, Gunma University School of Medicine, Maebashi, Japan; ${ }^{2}$ Department of Ophthalmology, Saku Central Hospital, Saku, Japan
Correspondence: Tomoyuki Kashima Department of Ophthalmology, Gunma University School of Medicine, 3-39-15 Showa-machi, Maebashi, Gunma 37I-85II, Japan

Tel $+8 \mid 272208338$

Fax +8I 53220384 I

Email kasimatomoyuki@yahoo.co.jp
Abstract: Rebamipide is an antiulcer agent used to treat gastric ulcer and gastritis. Biological effects of rebamipide include cytoprotection, wound healing, and anti-inflammatory properties that are known to be universal for a variety of tissues in addition to gastrointestinal mucosa. The therapeutic effects of rebamipide eye drops are due to its ability to increase corneal and conjunctival mucin-like substances and improve corneal and conjunctival injury in vivo. In this paper, we report a case of Sjögren's syndrome with complete disappearance of corneal erosion after administration of rebamipide eye drops. This was observed even though corneal erosion had not improved for 6 months after punctal occlusion surgery. The patient was a 33-year-old female, diagnosed with Sjögren's syndrome by a salivary gland biopsy. The corneal and conjunctival surfaces were filled with dense erosions, which did not improve with topical drugs. Punctal plugs were applied several times; however, the plugs were repeatedly shed. All four puncta of both eyelids were surgically occluded, and both corneal and conjunctival erosion was clearly improved. However, the erosion in the inferior cornea of both eyes had not improved for 6 months after surgery. We used the newly approved topical rebamipide for treatment of this patient. The corneal erosion gradually improved and completely disappeared 4 weeks after administration of the drug. Dry eye sensation disappeared at the same time. Both membrane-associated mucin and secreted mucin in the ocular surface are thought to be essential for maintenance of the tear film. Induction of mucin from ocular surface epithelium could be an effective treatment in cases of dry eye caused by mucin deficiency. Through its various mechanisms, rebamipide improves ocular surface conditions. To our knowledge, this is the first clinical case report using rebamipide ophthalmic solution. This drug may provide a novel approach to treat drying diseases of the eye.

Keywords: Sjögren's syndrome, dry eye, corneal erosion, rebamipide, Mucosta, mucin

\section{Introduction}

Dry eye disease is a multifocal disorder of tears and the ocular surface due to tear deficiency, excessive tear evaporation, and instability of tears. ${ }^{1}$ Tear-film instability is due to a disturbance in the ocular surface mucin leading to a dysfunction of mucin, resulting in dry eye. Mucins have several subtypes that are highly $O$-glycosylated glycoproteins with a high molecular weight. They are present on the apical surfaces of wet-surfaced epithelia, including the ocular surface, respiratory tract, esophagus, and gastrointestinal lining.

On the ocular surface, mucins are classified into two types. One is secreted mucin that is supplied from conjunctival goblet cells, and the other is membrane-associated mucin, which appears on the surface of the cornea and conjunctival epithelium. ${ }^{2}$ 
The roles of ocular surface mucin are to maintain tear film, lubricate the ocular surface, form the barrier function of the ocular surface, and remove pathogens. ${ }^{3-5}$

Rebamipide is an antiulcer agent used to treat gastric ulcer and gastritis since 1990 in Japan. ${ }^{6}$ Rebamipide has been shown to increase gastric endogenous prostaglandin E2 and $\mathrm{I} 2$, to promote gastric epithelial mucin, ${ }^{7,8}$ to behave as an oxygen-free radical scavenger, ${ }^{9,10}$ and to have other anti-inflammatory action. ${ }^{11-14}$ Biological effects of rebamipide include cytoprotection, wound healing, and anti-inflammatory properties that are known to be universal for a variety of tissues in addition to gastrointestinal mucosa. ${ }^{14}$ The clinical effectiveness of rebamipide for treatment of stomatitis, ${ }^{15}$ pulmonary, ${ }^{16}$ renal, ${ }^{17}$ and liver damage, ${ }^{18}$ colitis, ${ }^{19}$ and corneal protection ${ }^{20}$ have been shown by both basic and clinical research. ${ }^{14}$ This drug also accelerates healing of experimental gastric ulcers in Mongolian gerbils infected with Helicobacter pylori by improving cell kinetics, reducing apoptosis, and reducing inflammation. ${ }^{21}$

The therapeutic effects of rebamipide are due to its ability to increase corneal and conjunctival mucin-like substances and improve corneal and conjunctival injury in vivo. ${ }^{20}$ It is known that rebamipide increases the mucin production in cultured conjunctival goblet cells ${ }^{22,23}$ and in corneal epithelial cells. ${ }^{24}$ These reports have indicated that rebamipide increases secretion of both membrane-associated and secreted-type mucins. Rebamipide eye drops (Mucosta ophthalmic suspension UD2\%; Otsuka Pharmaceutical, Tokyo, Japan) for dry eye are being developed for approved use in the US. The drug has been approved in Japan since January 2012.

In this paper, we report a case of Sjögren's syndrome with complete disappearance of corneal erosion after administration of rebamipide eye drops. This was observed even though corneal erosion had not improved for 6 months after punctal occlusion surgery.

\section{Case presentation}

The patient was a 33-year-old female, diagnosed with Sjögren's syndrome at another hospital 5 years previously as a result of Schirmer's I test and positive anti-SS-A antibody (138.5 U/mL), though with negative anti-SS-B antibody. She had no history of rheumatoid arthritis, systemic lupus erythematosus, scleroderma, or primary biliary cirrhosis. The corneal and conjunctival surfaces were filled with dense erosions, which did not improve with topical artificial tears, hyaluronic acid, or antibiotic ointment (Figure 1). Her best corrected visual acuity was 20/20 in the right eye and 20/60 in the left eye at first visit. Tear secretion was evaluated at $0 \mathrm{~mm}$ in the right eye and $2 \mathrm{~mm}$ in the

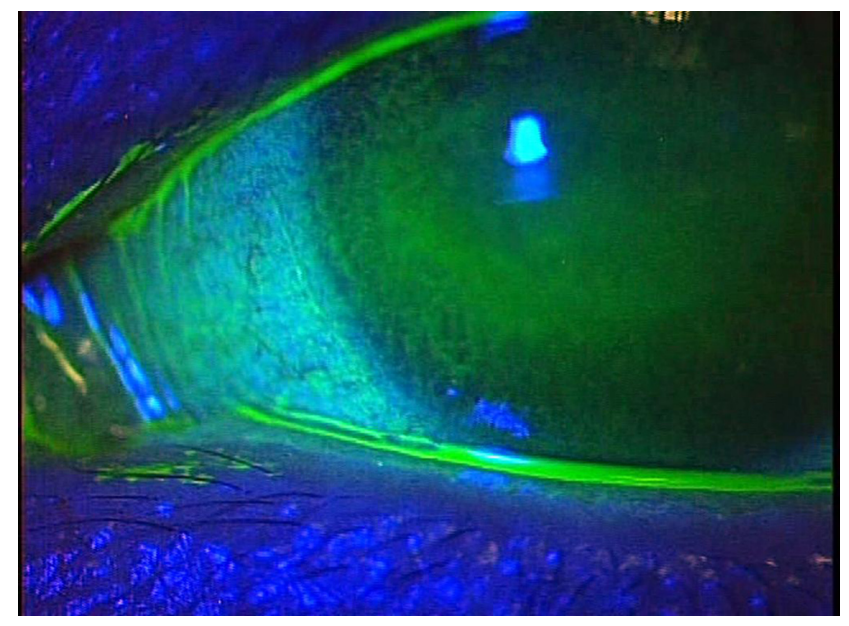

Figure I Slit lamp with fluorescence at the patient's first visit.

Notes: Dense erosion of both cornea and conjunctival surfaces did not resolve with any topical drugs and punctal plugs. Tear meniscus height was very low and the tear breakup was I-2 seconds because of ocular inflammation due to severe dry eye.

left by Schirmer's I test. Tear breakup time in both eyes was 1-2 seconds. Punctal plugs were applied several times to improve this condition; however, the puncta gradually dilated and plugs were repeatedly shed. Because punctal occlusion by plugs was not effective, all four puncta of both eyelids were surgically occluded by using monopolar electrocautery. The lacrimal puncta had completely disappeared, and recanalization of the lacrimal pathway had not occurred 6 months after surgery. The height of the tear meniscus had elevated, and both corneal and conjunctival erosion was clearly improved due to surgery. However, the erosion in the inferior cornea of both eyes had not improved 6 months after the operation in spite of using topical hyaluronic acid, ointment, and artificial tears (Figure 2). Tear breakup time was slightly

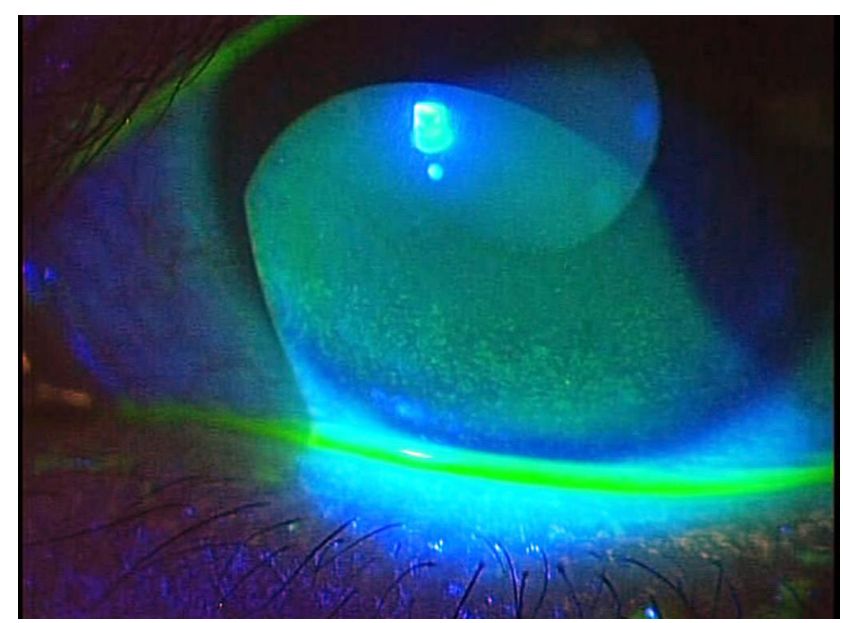

Figure 2 Slit lamp 6 months after surgical punctal occlusion.

Notes: Tear meniscus height increased, and erosion on the ocular surface improved. However, erosion on the lower part of the cornea remained. 
prolonged to 3 seconds; however, it still remained outside of normal ranges. We used the newly approved topical rebamipide for treatment of this patient. The corneal erosion gradually improved and completely disappeared 4 weeks after administration of the drug. The tear breakup time in both eyes increased to 8-10 seconds, and was within a normal range (Figure 3). Dry eye sensation disappeared at the same time, and then her best corrected visual acuity improved to $20 / 13$ in both eyes.

\section{Discussion}

Argueso et al reported the tear fluid of patients with Sjögren's syndrome reduced levels of goblet cell-specific mucin and levels of conjunctival mRNA. ${ }^{25}$ Both membrane-associated mucin and secreted mucin in the ocular surface are thought to be essential for maintenance of the tear film. Membraneassociated mucin is necessary for the spread of the tear film. Secreted mucin cannot spread over the site in the absence of membrane-associated mucin, such as occurs at an ulcer site. ${ }^{26}$ Drying or keratinization of the corneal and conjunctival epithelium are induced in diseases of the ocular surface, and accompanied by alteration of mucin production via mRNA expression, distribution, and character. Goblet cells are lost at the end stage of these diseases when there is total loss of both types of mucins on the surface of the eye. ${ }^{25,27,28}$ Induction of mucin from ocular surface epithelium could be an effective treatment in cases of dry eye caused by mucin deficiency. There are reports that rebamipide increases secretion of both membrane-associated and secreted mucins.

Previous studies have demonstrated that rebamipide has various inflammation-inhibitory effects, including

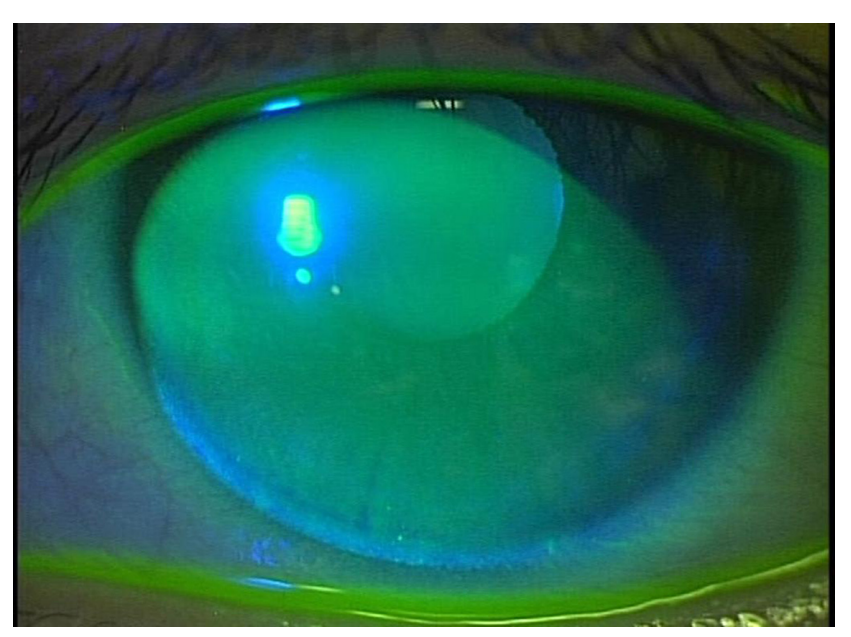

Figure 3 Four weeks after topical administration of rebamipide, the corneal erosion was completely resolved and the tears were clear without any debris or other evidence of inflammation.

Note: Tear breakup time was prolonged to normal ranges. suppression of inflammatory cytokine production by monocytes, ${ }^{29}$ suppression of free-radical scavenging activity, ${ }^{10}$ and suppression of CD $4 \mathrm{~T}$ cells and $\mathrm{T}_{\mathrm{h}} 1$ cytokines. ${ }^{30}$ In addition, rebamipide activates genes encoding such angiogenic growth factors as vascular endothelial growth factor and heparin-binding epidermal growth factor in cultured normal gastric mucosal cells, demonstrating a novel mechanism for its ulcer-healing action. ${ }^{31-33}$ Oral administration of rebamipide also affects all B-cell functions, and suppresses systemic secretion of $\operatorname{IgM}$ and $\operatorname{IgG} 1 .{ }^{30}$

Through its various mechanisms, rebamipide improves ocular surface conditions. Rebamipide eye drops immediately improved the patient's persistent corneal erosion after administration. Rebamipide eye drops may have a different mechanism of action when compared to preexisting drugs. Oral administration of rebamipide increases saliva volume for a mouse model of Sjögren's syndrome. ${ }^{30}$ Although tear secretion didn't increase in the same research, topical rebamipide may play an important role for the ocular surface of Sjögren's syndrome through mucin production. To our knowledge, this is the first clinical case report using rebamipide ophthalmic solution. This drug may provide a novel approach to treat drying and keratinizing diseases of the eye.

\section{Disclosure}

The authors have no financial interest related to this manuscript.

\section{References}

1. [No authors listed]. The definition and classification of dry eye disease: report of the Definition and Classification Subcommittee of the International Dry Eye WorkShop. Ocul Surf. 2007;5:75-92.

2. Gipson IK. Distribution of mucins at the ocular surface. Exp Eye Res. 2004; 78:379-388

3. Gipson IK, Argueso P. Role of mucins in the function of the corneal and conjunctival epithelia. Int Rev Cytol. 2003;231:1-49.

4. Fleiszig SM, Zaidi TS, Ramphal R, Pier GB. Modulation of Pseudomonas aeruginosa adherence to the corneal surface by mucus. Infect Immun 1994;62:1799-1804.

5. Blalock TD, Spurr-Michaud SJ, Tisdale AS, et al. Functions of MUC16 in corneal epithelial cells. Invest Ophthalmol Vis Sci. 2007;48: 4509-4518.

6. Uchida M, Tabusa F, Komatsu M, Morita S, Kanbe T, Nakagawa K Studies on $2(1 \mathrm{H})$-quinolinone derivatives as gastric antiulcer active agents. 2-(4-Chlorobenzoylamino)-3-[2(1H)-quinolinon-4-yl]propionic acid and related compounds. Chem Pharm Bull (Tokyo). 1985;33:3775-3786.

7. Kleine A, Kluge S, Peskar BM. Stimulation of prostaglandin biosynthesis mediates gastroprotective effect of rebamipide in rats. Dig Dis Sci. 1993; 38:1441-1449.

8. Yamasaki K, Kanbe T, Chijiwa T, Ishiyama H, Morita S. Gastric mucosal protection by OPC-12759, a novel antiulcer compound, in the rat. Eur J Pharmacol. 1987;142:23-29.

9. Naito Y, Yoshikawa T, Tanigawa T, et al. Hydroxyl radical scavenging by rebamipide and related compounds: electron paramagnetic resonance study. Free Radic Biol Med. 1995;18:117-123. 
10. Yoshikawa T, Naito Y, Tanigawa T, Kondo M. Free radical scavenging activity of the novel anti-ulcer agent rebamipide studied by electron spin resonance. Arzneimittelforschung. 1993;43:363-366.

11. Nebiki H, Higuchi K, Arakawa T, et al. Effect of rebamipide on Helicobacter pylori infection in patients with peptic ulcer. Dig Dis Sci. 1998;43:203S-206S.

12. Arakawa T, Kobayashi K. Quality of ulcer healing - a new concept to rank healed peptic ulcers. Gastroenterol Jpn. 1993;28 Suppl 5:158-162.

13. Higuchi K, Arakawa T, Nebiki H, et al. Rebamipide prevents recurrence of gastric ulcers without affecting Helicobacter pylori status. Dig Dis Sci. 1998;43:99S-106S

14. Arakawa T, Higuchi K, Fujiwara Y, et al. 15th anniversary of rebamipide: looking ahead to the new mechanisms and new applications. Dig Dis Sci. 2005;50 Supp1 1:S3-S11.

15. Matsuda T, Ohno S, Hirohata S, et al. Efficacy of rebamipide as adjunctive therapy in the treatment of recurrent oral aphthous ulcers in patients with Behçet's disease: a randomized, double-blind, placebo-controlled study. Drugs R D. 2003;4:19-28.

16. Ro JY, Kim JY, Kim KH. The inhibitory mechanism of rebamipide on the mediator release in the guinea pig lung mast cells activated with specific antigen-antibody reactions. Pharmacology. 2001;63:175-184.

17. Saad SY, Najjar TA, Al-Sohaibani MO. The effect of rebamipide on cisplatin-induced nephrotoxicity in rats. Pharmacol Res. 2000;42: 81-86.

18. Hong KW, Kim KE, Rhim BY, Lee WS, Kim CD. Effect of rebamipide on liver damage and increased tumor necrosis factor in a rat model of endotoxin shock. Dig Dis Sci. 1998;43:154S-159S.

19. Kishimoto S, Haruma K, Tari A, Sakurai K, Nakano M, Nakagawa Y. Rebamipide, an antiulcer drug, prevents DSS-induced colitis formation in rats. Dig Dis Sci. 2000;45:1608-1616.

20. Urashima H, Okamoto T, Takeji Y, Shinohara H, Fujisawa S. Rebamipide increases the amount of mucin-like substances on the conjunctiva and cornea in the N-acetylcysteine-treated in vivo model. Cornea. 2004; 23:613-619.

21. Watanabe T, Higuchi K, Hamaguchi M, et al. Rebamipide prevents delay of acetic acid-induced gastric ulcer healing caused by Helicobacter pylori infection in Mongolian gerbils. Dig Dis Sci. 2002;47:1582-1589.
22. Rios JD, Shatos M, Urashima H, Tran H, Dartt DA. OPC-12759 increases proliferation of cultured rat conjunctival goblet cells. Cornea. 2006;25: 573-581.

23. Rios JD, Shatos MA, Urashima H, Dartt DA. Effect of OPC-12759 on EGF receptor activation, p44/p42 MAPK activity, and secretion in conjunctival goblet cells. Exp Eye Res. 2008;86:629-636.

24. Takeji Y, Urashima H, Aoki A, Shinohara H. Rebamipide increases the mucin-like glycoprotein production in corneal epithelial cells. J Ocul Pharmacol Ther. 2012;28:259-263.

25. Argueso P, Balaram M, Spurr-Michaud S, Keutmann HT, Dana MR, Gipson IK. Decreased levels of the goblet cell mucin MUC5AC in tears of patients with Sjögren syndrome. Invest Ophthalmol Vis Sci. 2002;43:1004-1011.

26. Watanabe H. Significance of mucin on the ocular surface. Cornea. 2002; 21:S17-S22.

27. Nelson JD, Wright JC. Conjunctival goblet cell densities in ocular surface disease. Arch Ophthalmol. 1984;102:1049-1051.

28. Danjo Y, Watanabe H, Tisdale AS, et al. Alteration of mucin in human conjunctival epithelia in dry eye. Invest Ophthalmol Vis Sci. 1998;39: 2602-2609.

29. Aihara M, Imagawa K, Funakoshi Y, Ohmoto Y, Kikuchi M. Effects of rebamipide on production of several cytokines by human peripheral blood mononuclear cells. Dig Dis Sci. 1998;43:160S-166S.

30. Kohashi M, Ishimaru N, Arakaki R, Hayashi Y. Effective treatment with oral administration of rebamipide in a mouse model of Sjögren's syndrome. Arthritis Rheum. 2008;58:389-400.

31. Tarnawski A, Arakawa T, Kobayashi K. Rebamipide treatment activates epidermal growth factor and its receptor expression in normal and ulcerated gastric mucosa in rats: one mechanism for its ulcer healing action? Dig Dis Sci. 1998;43:90S-98S.

32. Udagawa A, Shiota G, Ichiba M, Murawaki Y. Effect of rebamipide on acetic acid-induced gastric ulcer in rats: involvement of hepatocyte growth factor. Scand J Gastroenterol. 2003;38:141-146.

33. Tarnawski AS, Chai J, Pai R, Chiou SK. Rebamipide activates genes encoding angiogenic growth factors and Cox2 and stimulates angiogenesis: a key to its ulcer healing action? Dig Dis Sci. 2004;49: 202-209.
Clinical Ophthalmology

\section{Publish your work in this journal}

Clinical Ophthalmology is an international, peer-reviewed journal covering all subspecialties within ophthalmology. Key topics include: Optometry; Visual science; Pharmacology and drug therapy in eye diseases; Basic Sciences; Primary and Secondary eye care; Patient Safety and Quality of Care Improvements. This journal is indexed on

\section{Dovepress}

PubMed Central and CAS, and is the official journal of The Society of Clinical Ophthalmology (SCO). The manuscript management system is completely online and includes a very quick and fair peer-review system, which is all easy to use. Visit http://www.dovepress.com/ testimonials.php to read real quotes from published authors. 